\title{
A case of Bruton's disease presenting with recurrent pneumonia
}

\author{
Fatih Akin $^{1 *}$, Saltuk Bugra Boke ${ }^{1}$, Ece Selma Solak ${ }^{1}$, Cengizhan Kılıcaslan $^{1}$, Sukru Arslan $^{2}$ \\ ${ }^{1}$ Department of Pediatrics, Konya Education and Research Hospital, Konya, Turkey; \\ *Corresponding Author: drfatihakin@gmail.com \\ ${ }^{2}$ Department of Pediatric Nephrology, Konya Education and Research Hospital, Konya, Turkey
}

Received 9 July 2013; revised 3 August 2013; accepted 10 August 2013

Copyright (C) 2013 Fatih Akin et al. This is an open access article distributed under the Creative Commons Attribution License, which permits unrestricted use, distribution, and reproduction in any medium, provided the original work is properly cited.

\begin{abstract}
$X$-linked agammaglobulinemia also known as Bruton's disease, is a humoral immunodeficiency disease characterized by recurrent bacterial infections due to low levels or absence of serum immunoglobulins. It has been shown to be caused by mutations in the gene encoding Bruton tyrosine kinase. Although bacterial infections typically begins 6 - 9 months after birth when maternal IgG is reduced below the protective level, the diagnosis is established before 5 years of age. Here we report a case with Bruton's disease and recurrent pneumonia that is typical of the late diagnosed disease. This report suggests the importance of evaluating patients with recurrent infections for immunodeficiency diseases.
\end{abstract}

Keywords: X-Linked Agammaglobulinemia; Recurrent Pneumonia; Immunodeficiency

\section{INTRODUCTION}

$\mathrm{X}$-linked agammaglobulinemia (XLA) also called as a Bruton's disease, is a humoral immunodeficiency disease described by Bruton in 1952 [1]. It is characterized by recurrent bacterial infections due to low levels or absence of serum immunoglobulins. It has been shown to be caused by mutations in the gene encoding Bruton's tyrosine kinase (Btk). The incidence of XLA is reported to be around 1/200,000 male births [2].

The onset of recurrent bacterial infections typically begins 6 - 9 months after birth when maternal IgG is reduced below the protective level. Although the diagnosis of immunodeficiency is established before the age of 5 years, with a careful clinical awareness the diagnosis can be made in the first year of the life [1].
Pneumonia is inflammation of the parenchyma of the lungs. It is fairly common especially in developing countries and is a substantial cause of childhood morbidity and mortality. Recurrent pneumonia is usually defined as two or more episodes of pneumonia in a year, or 3 episodes in any time period [3,4].

Here we report a case with Bruton's disease and recurrent pneumonia that is typical of the late diagnosed disease. This report suggests the importance of evaluating patients with recurrent infections for immunodeficiency diseases.

\section{CASE REPORT}

A seven-year-old boy was referred with fever, coughing and fatigue. He had received ampisillin-sulbactam and clarythromycine with the diagnosis of pneumonia and acute otitis media for three days at a local hospital. It was learned that he had previously been hospitalised for pneumonia for five times, had bilateral otitis media which was treatment-resistant for the last two years and had been suffering from upper air way infection 8 - 10 times per year. The first hospitalization for pneumonia was at the age of 15-month-old. He was the first child of non-consanguineous parents and had a healthy threeyear-old brother and ten-month-old sister. He was born 3200 gr at term with normal delivery. There was no family history of immundeficiencies.

On physical examination, weekness and pallor was remarkable. His weight was under the 3rd percentile. The body temperature was $36.8^{\circ} \mathrm{C}$. He had a blood pressure of 100/60 mmHg and pulse rate of 98/min. Bilateral purulent otorrhea was observed on ear examination. Bilateral diminished breath sounds with rales were detected by auscultation of the lungs. There were no palpable lymph nodes and tonsillar tissue was hypoplasic.

Laboratory tests were as follows: white blood cells, 3850/mL (neutrophils 88\% and lymphocytes 12\%); he- 
moglobulin, $8 \mathrm{~g} / \mathrm{dL}$; platelets, $357 \times 10^{3} / \mathrm{mL}$; sedimentation rate, $98 \mathrm{~mm} / \mathrm{s}$; CRP, $115 \mathrm{mg} / \mathrm{L}$, serum immunoglobulin (Ig)G, IgA and IgM levels, 145 (normal range: 340 - 1200), 26 (30 - 230), and 29 (40 - 200) mg/dL, respectively. Markedly reduced levels of B cells (CD 19+ cells) in the peripheral circulation $(0.06 \%)$ were observed by flow cytometric analysis. Biochemical and urine analysis were within normal levels. Antibodies against viral pathogens including cytomegalovirus, herpes simplex virus, rubella, toxoplasma, parvovirus B19 and hepatitis A, B, C viruses were negative. The results of the cultures of blood, sputum, throat and urine were also negative. His chest radiography and computed tomography findings revealed bilateral infiltrations, consolidations and a small amount of left pleural effusion (Figure 1). Sweat testing and mutation analysis were negative for cystic fibrosis. Echocardiographic examination for congenital heart diseases was normal.

After admission to the hospital cefoperazone/sulbactame and teicoplanin were started intravenously. The history of recurrent pneumonias requiring hospitalization and recurrent otitis media, hypogammaglobulinemia with the deficiency of CD19 B cells, absence of palpable lymph nodes and hypoplasic tonsils suggested that our patient had XLA. On the third day of the hospitalization intravenous immunoglobulin (IVIG) $2 \mathrm{gr} / \mathrm{kg}$ was given in two days. On the fourteenth day of admission the patient was totally recovered and discharged with a treatment schedule of monthly gammaglobulin injections in dosages of $0.4 \mathrm{gr} / \mathrm{kg}$.

\section{DISCUSSION}

Almost $60 \%$ of patients with XLA are diagnosed when they develop a severe infection. The most common infections seen in XLA patients include recurrent pneumonia, empyema, sinusitis, recurrent otitis, sepsis, recurrent meningitis or septic arthritis [1,5,6]. Although bacterial infections typically begins 6 - 9 months after birth when maternal IgG is reduced below the protective level, the diagnosis of XLA is established before 5 years of age [1]. Present case is a late diagnosed one at the age of seven years old.

Recurrent pneumonia is defined as two or more epi-

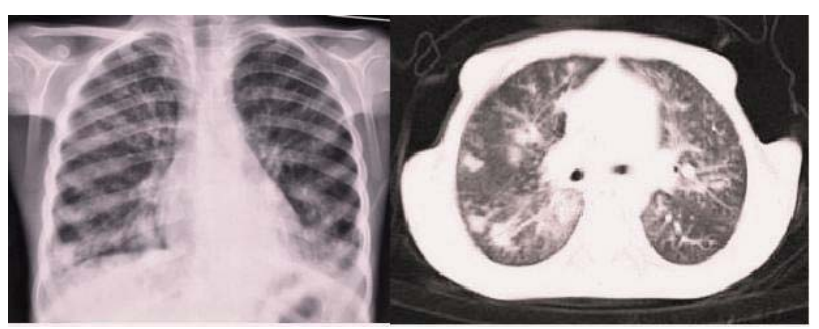

Figure 1. Chest radiography and computed tomography showing bilateral infiltrations and consolidations. sodes of pneumonia in a year, or 3 or more ever $[3,4]$. Patients with recurrent pneumonia should be evaluated for underlying diseases including asthma, congenital heart disease, gastroesophageal reflux, foreign body aspiration, structural anomalies, cystic fibrosis and immunodeficiency. Owayed et al. and Lodha et al. reported that $10 \%$ and $15.7 \%$ of the patients with recurrent pneumonia had an underlying disease of immunodeficiency, respectively $[3,4]$. A study conducted in Turkey demonstrated that $10 \%$ of 71 cases with recurrent pneumonia had immunodeficiency [7]. Chun et al. reported that $68.4 \%$ and $31.4 \%$ of 19 patients with XLA had pneumonia and acute otitis media leading to hospitalization [5]. Our case also had a history of recurrent pneumonia and treatment-resistant otitis media suggesting the necessity of evaluating patients with recurrent infections for immunodeficiency diseases.

$\mathrm{XLA}$ is a rare genetic disorder in which the development of B cells is arrested during differentiation. The gene responsible for this order was identified in 1993 as Btk [8]. Although early diagnosis has been made possible by genetic analysis of the Btk, identifying mutation is not absolutely necessary for the diagnosis [5]. Wang et al. reported that Btk gene mutation was not identified from 4 of the 16 patients with XLA [8]. The history of recurrent pneumonias requiring hospitalization and recurrent otitis media, hypogammaglobulinemia with the deficiency of CD19 B cells, absence of palpable lymph nodes and hypoplasic tonsils suggested the diagnosis of XLA in our patient.

In conclusion, pneumonia is one of the most common reasons for referral to pediatric physicians. Our case emphasises that patients with recurrent pneumonia should be evaluated carefully for immunodeficiency diseases, because delay in diagnosis and treatment can result in severe illness or death.

\section{REFERENCES}

[1] Lee, K.H., Shyur, S.D., Chu, S.H., Huang, L.H., Kao, Y.H., Lei ,W.T., et al. (2011) Clinical manifestations and BTK gene defect in 4 unrelated Taiwanese families with Bruton's disease. Asian Pacific Journal of Allergy and Immunology, 29, 260-265.

[2] Váncsa, A., Tóth, B. and Szekanecz, Z. (2011) BTK gene mutation in two non-identical twins with X-linked agammaglobulinemia associated with polyarticular juvenile idiopathic arthritis. Israel Medical Association Journal, 13, 579-580.

[3] Lodha, R., Puranik, M., Natchu, U.C., and Kabra, S.K. (2002) Recurrent pneumonia in children: Clinical profile and underlying causes. Acta Paediatrica, 91, 1170-1173. doi:10.1111/j.1651-2227.2002.tb00123.x

[4] Owayed, A.F., Camphell, D.M., and Wang, E.E.L. (2000) Underlying causes of recurrent pneumonia in children. Archives of Pediatrics \& Adolescent Medicine, 154, 190- 
194. doi:10.1001/archpedi.154.2.190

[5] Chun, J.K., Lee, T.J., Song, J.W., Linton, J.A. and Kim, D.S. (2008) Analysis of clinical presentations of Bruton disease: A review of 20 years of accumulated data from pediatric patients at Severance Hospital. Yonsei Medical Journal, 49, 28-36. doi:10.3349/ymj.2008.49.1.28

[6] Kanra, G., Arslan, S., Ergin, M., Tarim, O., Yurdakok, M., Secmeer, G., et al. (1987) Recurrent purulent meningitis in a patient with Bruton's disease. Turkish Journal of Pediatrics, 29, 107-110.
[7] Ciftci, E., Gunes, M., Koksal, Y., Ince, E., and Dogru, U. (2003) Underlying causes of recurrent pneumonia in Turkish children in a university hospital. Journal of Tropical Pediatrics, 49, 212-215. doi:10.1093/tropej/49.4.212

[8] Wang, Y., Kanegane, H., Sanal, O., Ersoy, F., Tezcan, I., Futatani, T., et al. (2001) Bruton tyrosine kinase gene mutations in Turkish patients with presumed X-linked agammaglobulinemia. Human Mutation, 18, 356. 